\title{
Development of a micro-sward technique for determining intake characteristics of perennial ryegrass varieties
}

\author{
R.J. Orr*, K.L. Young, J.E. Cook \& R.A. Champion \\ Institute of Grassland and Environmental Research, North Wyke, Okehampton, Devon, U.K. \\ (*author for correspondence: e-mail: robert.orr@bbsrc.ac.uk)
}

Received 11 May 2004; accepted 26 October 2004

Key words: bite mass, cattle, sward boxes, perennial ryegrass

\begin{abstract}
Summary
Two diploid (Belramo and Glen), one tetraploid (Rosalin) and one tetraploid hybrid (Loli um $\times$ boucheanum Kunth) (AberExcel) intermediate-heading perennial ryegrass (Lolium perenne L.) varieties were sown in boxes $(85 \times 44 \times 14$ $\mathrm{cm})$ to create micro-swards. Once established, these were defoliated at approximately 21-day intervals before being offered to individual yearling Simmental $\times$ Holstein beef heifers in short-term tests. Bite mass measured in these tests was compared with bite mass for groups of similar heifers which were rotationally stocked on the same four varieties. The boxes were weighed $( \pm 0.1 \mathrm{~g})$ before and after a period during which the heifers were allowed to take approximately 50 bites. The micro-sward methodology was developed in 2002 and bite masses for Belramo, Glen, Rosalin and AberExcel, respectively, were 0.44, 0.46, 0.49 and $0.50 \mathrm{~g} \mathrm{DM}$ bite $^{-1}$ compared with $0.48,0.49$, 0.50 and $0.50 \mathrm{~g} \mathrm{DM}$ bite $^{-1}$ measured for rotationally stocked cattle. In 2003, the values for bite mass were 0.40 , $0.41,0.41$ and $0.43 \mathrm{~g} \mathrm{DM}_{\text {bite }}{ }^{-1}$ measured using sward boxes and $0.31,0.41,0.34$ and $0.37 \mathrm{~g} \mathrm{DM}^{\text {bite }}{ }^{-1}$ for rotationally stocked cattle. Whilst the rankings were similar within ploidy for the two assessment methods, there were no significant differences between the varieties. The micro-sward methodology provides a rapid, low-cost assessment method with a low seed requirement to screen for intake traits during breeding programmes and during variety evaluation. Now there is a need to develop further this methodology in order to allow small-scale simulation of other defoliation regimes, for example continuous stocking.
\end{abstract}

\section{Introduction}

The assessment of intake characteristics of grass cultivars in grazing trials (e.g. Barrett et al., 2003; Hazard et al., 1998; Orr et al., 2003) is expensive in terms of land, animal and labour resources. Various small-scale intake assessment methodologies have been reported in the literature where sward canopies of various forms have been presented to animals. These include artificially-created sward boards (e.g. Black \& Kenney, 1984; Laca et al., 1992a, b), turves cut from pasture and placed in trays (e.g. Concha \& Nicol, 2000; Newman et al., 1992) or swards grown from seeds in trays (e.g. Mitchell et al., 1991). Construction of sward boards is labour-intensive. Turves require some form of an- choring if they are not to be uprooted, e.g. cutting the sward short, placing a metal grid through the stubble so that it is located at the soil surface - but this may affect the test animals. Alternatively, the roots may be allowed to penetrate an under-layer of growing medium, but this would require time. The aim of this study was to develop and test a low-cost methodology to screen grass variety intake attributes in short-term tests with individual cattle offered perennial ryegrass (Lolium perenne L.) grown in boxes. These were compared with measurements made at a field scale for groups of cattle grazing 1-day paddocks throughout the grazing season to see if bite mass measured for individuals in short-term tests related in any systematic way to that measured for the groups. If successful, 
this proposed sward box technique would have a relatively low requirement for seed, which may be in short supply early on in the breeding programmes (Beerepoot \& Agnew, 1997), and could be used to identify material with useful intake attributes at an early stage.

\section{Materials and methods}

\section{Grass varieties}

Perennial ryegrass varieties were chosen which previously (Orr et al., 2003) had shown high or low intake characteristics when grazed by sheep under continuous stocking management. Four intermediate-heading perennial ryegrass (Lolium perenne L.) varieties (Belramo and Glen (diploid), Rosalin (tetraploid) and AberExcel (tetraploid hybrid, Lolium $\times$ boucheanum Kunth) were used and, respectively, daily intakes by sheep had been 810, 904, 818 and $1104 \mathrm{~g}$ dry matter.

\section{Micro-sward establishment}

The four varieties were each sown separately in five replicate plastic boxes $(85 \mathrm{~cm} \times 44 \mathrm{~cm} \times 14 \mathrm{~cm}$, weighing $3 \mathrm{~kg}$ when empty) on 25 July 2002 (20 boxes) and 2 May 2003 (20 boxes). To eliminate the risk of losing drainage water and growing medium while weighing the boxes drainage holes were absent, but a drainage layer of $10 \mathrm{~kg}$ of pea gravel was placed at the base of the box. Each box was filled with a loam-based compost (John Innes No. 3; http://www.jic.bbsrc.ac.uk/) containing peat, sand and nutrients. Thirty eight and $47 \mathrm{~kg}$ of compost were used in 2002 and 2003, respectively. The declared nutrient concentrations ranges for the compost were for N (201-240 ppm), P (161$200 \mathrm{ppm})$ and K (321-360 ppm) respectively. No further nutrients were added between sowing and the tests. A plastic mesh $(50 \mathrm{~mm} \times 30 \mathrm{~mm}$ openings $)$ was placed within the compost, positioned $7 \mathrm{~cm}$ below the surface. This was intended to ensure that, once the roots had penetrated and enveloped the mesh, individual tillers were less likely to be pulled out by the cattle.

The seeds were sown at a rate of 1600 seeds $\mathrm{m}^{-2}$, using a temporary grid comprising $25 \mathrm{~mm} \times 25 \mathrm{~mm}$ squares placed on top of the compost surface to ensure a uniform distribution of plants across the box. Sowing dates are shown in Table 1. In order to control the quantity and frequency of watering, the boxes were kept in a glasshouse in 2002 and a polytunnel in 2003.

\section{Micro-sward management}

In both years, once the swards were deemed subjectively to be well established in terms of height and tillering they were cut using scissors to $6 \mathrm{~cm}$ above the root/shoot interface using a graduated vertical markerguide on the dates shown as Harvest 1 in Table 1. This meant that in 2002 the first harvest was taken approximately 34 days after sowing and, in 2003, 46 days after sowing. Subsequent to the first harvest the aim was to defoliate at approximately 21-day intervals. The actual intervals are shown in Table 1. The objective of this management was to encourage rapid tillering and increase the sward density so as to simulate as closely as possible a well-established sward in field conditions. Following the final 16-19-day (2002) and 21day (2003) regrowth periods, the micro-swards were tested, having been moved outdoors to a test arena on the day before each test.

\section{Experimental design}

Each variety was offered to each of the heifers in a $4 \times 4$ Latin-square design with 4 periods (days) $(2,3,4$ and 7 October 2002 and 18, 19, 20 and 21 August 2003). The order in which the tests on each of the four varieties were conducted within any day was randomised. A test arena $(3 \mathrm{~m} \times 3 \mathrm{~m})$ was set up on a concrete pad using standard cattle hurdles. The heifers were trained to become accustomed to this arena before the tests. In 2002 they were offered freshly cut grass, in similar boxes to those used in the tests. In 2003, the micro-swards from the previous year were used and were offered in a systematic rota that mirrored the subsequent test schedule. The micro-swards were placed on the floor of the arena so that the root/shoot interface was approximately $14 \mathrm{~cm}$ above the level at which the heifers were standing.

\section{Animals}

Four yearling Simmental $\times$ Holstein heifers were used for the micro-sward tests in each year. The mean weights of the heifers at the time of the tests were $329 \pm 17.2 \mathrm{~kg}$ and $296 \pm 9.2 \mathrm{~kg}$ for 2002 and 2003, respectively. Prior to the tests they grazed perennial 


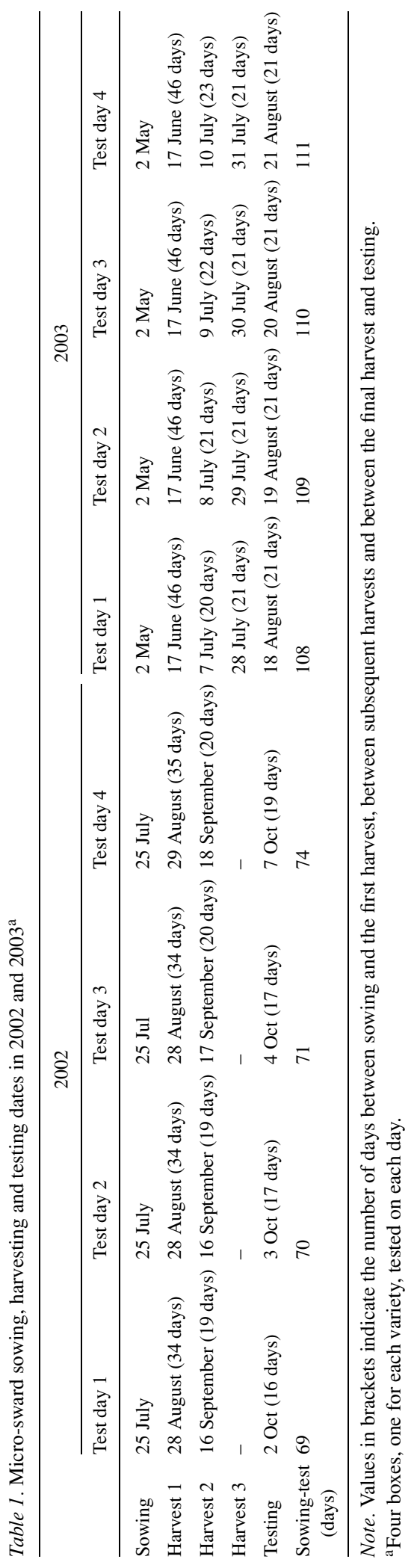


ryegrass swards, but did not graze the test varieties. The heifers were kept on a paddock adjacent to the test arena to ensure they were not fasted before each test so that this did not affect their intake (Greenwood \& Demment, 1988; Newman et al., 1994; Patterson et al., 1998).

\section{Measurements}

Grass from harvest 2 in 2002 and harvest 3 in 2003 was oven-dried at $85^{\circ} \mathrm{C}$ for $18 \mathrm{~h}$ and weighed in order to assess dry matter (DM) yield.

Immediately before each test, ten tillers were cut at the root/shoot interface from each micro-sward and the sheath tube and lamina lengths of live leaves were measured using a ruler. Lamina samples designed to be representative of the material grazed were also taken, subsequently oven-dried at $85^{\circ} \mathrm{C}$ for $18 \mathrm{~h}$ and weighed to obtain DM concentration.

Before each test the entire exterior surface of each box was wiped clean to remove any soil, water or any other extraneous material in order to ensure that this material did not become detached during the test and bias results. Each heifer was then admitted to the arena and allowed to take approximately 50 bites from the micro-sward, with the actual number of bites recorded visually. Video and audio recordings were also made of each test and the number of bites counted during the test was subsequently verified from the recordings. During the tests a companion heifer, chosen at random from the other 3 was placed in a pen close and visible to the test heifer

Before and after each test, the sward boxes were weighed to an accuracy of $\pm 0.1 \mathrm{~g}$ inside a wind-proof enclosure to minimise air-disturbance of the balance (IS1501GG-S0CE, Sartorius AG). An ungrazed control box of the same variety as that being tested was also weighed before and after each test in order to correct for evapo-transpiration losses during the test period. For the first three periods the boxes that were to be grazed in the next test period were used as the controls. For the final test period the fifth box of each variety was used as a control. Bite mass was calculated on both fresh and DM bases from the number of bites, the corrected weight change of the boxes and the DM concentration of the laminae.

Bite mass for rotationally stocked heifers grazing in groups in 1-day paddocks (each 0.02 ha) was measured using a weighing technique, described in detail by Orr et al. (2004a). The compressed sward height, measured using a rising platemeter (Ashgrove Pastoral Products,
Palmerston North, New Zealand) when the cattle entered the paddock was approximately $11-13 \mathrm{~cm}$ and this was reduced to approximately $6-7 \mathrm{~cm}$ at the end of the grazing period. Measurements were made on two out of four heifers in each of 12 groups (3 replicates of each of the four varieties). Measurements were made in replicate blocks on each of 3 days (10, 11 and 12 September 2002 and 22, 26 and 27 August 2003). Mean weight of the heifers was $328 \pm 3.5 \mathrm{~kg}$ and $316 \pm 5.1$ $\mathrm{kg}$ in 2002 and 2003, respectively.

\section{Statistical analysis}

\section{Micro-swards}

The experiments were analysed within year using analysis of variance for a $4 \times 4$ Latin square design with Genstat 5 (Lawes Agricultural Trust, 1995). Grass yield in the harvest preceding the tests was analysed using a one-way analysis of variance $(n=16)$. The effects of ploidy and variety within ploidy were examined by using orthogonal contrasts.

\section{Groups of heifers}

Bite mass was analysed as a randomised block design, with ploidy and variety within ploidy fitted as orthogonal contrasts. Mean values for the two measured heifers in each of the 12 groups were used as the unit of replication.

\section{Results}

Dry matter yield

DM yields (above $6 \mathrm{~cm}$ ) at the final harvest before the tests (Table 2) did not differ significantly between ploidys or between varieties within ploidy in either year of the experiment.

\section{Method development in 2002}

Mean times of the four tests on each day (time of the first weighing of the micro-sward) were 09.45, 11.15, 14.20 and 14.35 h British Summer Time in 2002. The mean weight ( \pm s.e.) of the micro-swards at the start was $52.8 \pm 0.65 \mathrm{~kg}$ and the mean weight loss over the test period $($ mean $=8 \mathrm{~min}$ ) was $207.7 \pm 13.27 \mathrm{~g}$. The control micro-swards lost $10.6 \pm 1.14 \mathrm{~g}$ through evapotranspiration over a similar period (mean $1.54 \pm$ $0.17 \mathrm{~g} \mathrm{~min}^{-1}$ ). Thus the mean adjusted weight of fresh grass removed was $196.6 \pm 12.95 \mathrm{~g}$. The heifers ate 
Table 2. Dry matter (DM) yield for the harvest preceding the sward box tests in 2002 and 2003

\begin{tabular}{|c|c|c|c|c|c|c|c|c|}
\hline & \multirow[b]{2}{*}{ Belramo $(d)$} & \multirow[b]{2}{*}{ Glen $(d)$} & \multirow[b]{2}{*}{ Rosalin $(t)$} & \multirow[b]{2}{*}{ AberExcel $(t h)$} & \multirow[b]{2}{*}{ s.e.d } & \multicolumn{3}{|c|}{ F probability } \\
\hline & & & & & & Ploidy & Belramo vs. Glen & AberExcel vs. Rosalin \\
\hline \multicolumn{9}{|c|}{ Yield $\left(\mathrm{g} \mathrm{DM} \mathrm{m}^{-2}\right)$} \\
\hline 2002 & 187 & 203 & 185 & 214 & 43.9 & 0.880 & 0.732 & 0.532 \\
\hline 2003 & 214 & 229 & 190 & 216 & 19.7 & 0.210 & 0.460 & 0.203 \\
\hline
\end{tabular}

Note. $(d)$ diploid; $(t)$ tetraploid; $(t h)$ tetraploid hybrid.

readily from the sward boxes taking $51.2 \pm 0.41$ bites in each test.

The dimensions of the tillers sampled before each test in October 2002 are shown in Table 3. Whilst the lengths of the oldest and 2nd oldest fully-expanded live leaves and their associated sheath tubes tended to be greater for the tetraploid varieties than the diploids, only that of the expanding leaves was significantly different $(F$ prob. $=0.003)$. AberExcel had significantly longer $(F$ prob. $=0.043)$ expanding leaves than Rosalin. Grass DM\% tended to be lower for the tetraploid varieties than the diploids, whereas bite mass tended to be higher on a fresh and DM basis but these effects were not significant.

The values for DM bite mass for the groups of cattle measured in September 2002 were 0.48 (Belramo), 0.49 (Glen), 0.50 (Rosalin) and 0.50 (AberExcel) g DM bite $^{-1}, F$ prob. $\left.=0.988\right)$ and these values were very similar to those measured using sward boxes (Table 3 ).

\section{Sward box tests in 2003}

Mean times of the four tests on each day (time of first weighing of the micro-sward) were $09.45,11.35,14.10$ and $14.30 \mathrm{~h} \mathrm{BST}$ in 2003 . The mean weight ( \pm s.e.) of the micro-swards at the start was $64.2 \pm 0.80 \mathrm{~kg}$ and the mean weight loss over the test period (mean $=4$ min) was $150.8 \pm 6.74 \mathrm{~g}$. The control micro-swards lost $17.1 \pm 0.27 \mathrm{~g}$ by evapotranspiration losses over a similar period (mean $2.39 \pm 0.27 \mathrm{~g} \mathrm{~min}^{-1}$ ). Thus the mean adjusted weight of the fresh grass removed was $140.9 \pm 7.45 \mathrm{~g}$. The heifers ate readily from the sward boxes taking $51.4 \pm 0.38$ bites in each test.

The dimensions of the tillers sampled before each test in 2003 are shown in Table 4. As in 2002, the lengths of the oldest and 2nd oldest fully-expanded live leaves and their associated sheath tubes were not significantly different but, unlike 2002, that of the expanding leaves tended to be longer $(F$ prob. $=0.087)$

Table 3. Sheath tube length, leaf length, grass dry matter (DM)\% and bite mass for perennial ryegrass grown in boxes and offered to individual heifers in short-term tests in October 2002

\begin{tabular}{|c|c|c|c|c|c|c|c|c|}
\hline & \multirow[b]{2}{*}{ Belramo $(d)$} & \multirow[b]{2}{*}{ Glen $(d)$} & \multirow[b]{2}{*}{ Rosalin $(t)$} & \multirow[b]{2}{*}{ AberExcel $(t h)$} & \multirow[b]{2}{*}{ s.e.d } & \multicolumn{3}{|c|}{ F probability } \\
\hline & & & & & & Ploidy & Belramo vs. Glen & AberExcel vs. Rosalin \\
\hline \multicolumn{9}{|c|}{ Sheath tube length $(\mathrm{cm})$} \\
\hline Oldest & 5.8 & 5.8 & 5.8 & 6.9 & 0.78 & 0.359 & 0.998 & 0.210 \\
\hline 2nd oldest & 7.0 & 6.9 & 7.5 & 7.4 & 0.79 & 0.260 & 0.933 & 0.621 \\
\hline \multicolumn{9}{|l|}{ Leaf length $(\mathrm{cm})$} \\
\hline Oldest & 10.4 & 8.0 & 11.5 & 14.1 & 3.09 & 0.152 & 0.468 & 0.424 \\
\hline 2nd oldest & 19.3 & 19.9 & 25.7 & 26.0 & 5.39 & 0.097 & 0.912 & 0.649 \\
\hline Expanding & 16.5 & 15.0 & 18.6 & 22.1 & 1.39 & 0.003 & 0.317 & 0.043 \\
\hline DM\% & 13.2 & 13.1 & 12.3 & 11.8 & 1.70 & 0.391 & 0.956 & 0.795 \\
\hline \multicolumn{9}{|l|}{ Bite mass } \\
\hline$\left(\mathrm{g}\right.$ fresh bite $\left.{ }^{-1}\right)$ & 3.39 & 3.50 & 4.16 & 4.32 & 0.598 & 0.107 & 0.863 & 0.796 \\
\hline$\left(\right.$ g DM bite $\left.^{-1}\right)$ & 0.44 & 0.46 & 0.49 & 0.50 & 0.032 & 0.082 & 0.518 & 0.690 \\
\hline
\end{tabular}

Note. $(d)$ diploid, $(t)$ tetraploid, $(t h)$ tetraploid hybrid. 
Table 4. Sheath tube length, leaf length, grass DM\% and bite mass for perennial ryegrass grown in boxes and offered to individual heifers in short-term tests in August 2003

\begin{tabular}{|c|c|c|c|c|c|c|c|c|}
\hline & \multirow[b]{2}{*}{ Belramo $(d)$} & \multirow[b]{2}{*}{ Glen $(d)$} & \multirow[b]{2}{*}{ Rosalin $(t)$} & \multirow[b]{2}{*}{ AberExcel ( $t h)$} & \multirow[b]{2}{*}{ s.e.d } & \multicolumn{3}{|c|}{ F probability } \\
\hline & & & & & & Ploidy & Belramo vs. Glen & AberExcel vs. Rosalin \\
\hline \multicolumn{9}{|c|}{ Sheath tube length $(\mathrm{cm})$} \\
\hline Oldest & 7.2 & 6.7 & 6.0 & 6.6 & 0.54 & 0.129 & 0.402 & 0.321 \\
\hline 2nd oldest & 8.7 & 8.0 & 6.8 & 7.6 & 0.70 & 0.065 & 0.365 & 0.290 \\
\hline \multicolumn{9}{|l|}{ Leaf length $(\mathrm{cm})$} \\
\hline Oldest & 17.8 & 14.7 & 13.9 & 13.8 & 3.05 & 0.310 & 0.354 & 0.975 \\
\hline 2nd oldest & 33.5 & 29.7 & 31.3 & 31.4 & 1.93 & 0.858 & 0.099 & 0.982 \\
\hline Expanding & 12.1 & 13.9 & 14.5 & 19.0 & 2.60 & 0.087 & 0.522 & 0.136 \\
\hline DM\% & 16.0 & 15.2 & 14.9 & 14.2 & 0.75 & 0.091 & 0.319 & 0.430 \\
\hline \multicolumn{9}{|l|}{ Bite mass } \\
\hline$\left(\mathrm{g}\right.$ fresh bite $\left.{ }^{-1}\right)$ & 2.50 & 2.68 & 2.72 & 3.04 & 0.151 & 0.034 & 0.277 & 0.078 \\
\hline$\left(\mathrm{g}\right.$ DM bite $\left.{ }^{-1}\right)$ & 0.40 & 0.41 & 0.41 & 0.43 & 0.030 & 0.538 & 0.858 & 0.402 \\
\hline
\end{tabular}

Note. $(d)$ diploid, $(t)$ tetraploid, $(t h)$ tetraploid hybrid.

for tetraploids than diploids. Grass DM\% tended to be lower for the tetraploid varieties than the diploids, whereas bite mass tended to be higher on a fresh and DM basis, but these effects were not significant.

The values for DM bite mass for the groups of similar cattle measured in August 2003 were 0.31 (Belramo), 0.41 (Glen), 0.34 (Rosalin) and 0.37 (AberExcel) g DM bite ${ }^{-1}, F$ prob. $\left.=0.113\right)$. The rankings were similar to those measured using sward boxes (Table 4).

\section{Discussion}

\section{Growing micro-swards in boxes}

Growing the swards in boxes proved to be successful in both years. The choice of box dimensions was influenced by a requirement for having sufficient rooting depth for the grass plants and providing sufficient area so that the cattle could take enough bites without encountering excessive depletion of the canopy. Examination after the micro-sward tests indicated the depth of growing medium chosen $(14 \mathrm{~cm})$ was appropriate and a well developed rooting system was established. The provision of a plastic mesh within the growing medium meant that no tillers were uprooted during any of the tests.

In previous measurements Rook et al. (2004) reported that cattle of similar age and weight to those used here, with an incisor arcade breadth of $71.5 \mathrm{~mm}$, had an 'apparent' (allowing for the fact that bites can overlap (Ungar \& Ravid, 1999)) bite area of $36.4 \mathrm{~cm}^{2}$.
These cattle had an apparent bite depth which was proportionately 0.35 of the sward surface height $(7.7 \mathrm{~cm})$. In the present experiment, the area of the boxes used $\left(3740 \mathrm{~cm}^{2}\right)$ was thus equivalent to 102 potential bites, compared with the 50-bite target used for the tests. During the training period in 2003, the heifers were allowed to graze the micro-sward unrestricted, they took between 150 and 250 bites before pausing and in most cases the micro-swards had been reduced to a stubble of approximately $6 \mathrm{~cm}$. This meant that they were disposed to take many more (overlapping) bites than they were allowed to in the tests. A refinement of the methodology would be to allow the heifers to take further bites than just 50 and then successively reweigh the box, so that the bite mass response curves could be established for a large number of contrasting varieties as sward height/mass is reduced (Barrett et al., 2001; McGilloway et al., 1999; Orr et al., 2004a) as would be the case in rotationally-stocked swards. This might reveal further differences between varieties in sheath tube length as this has been shown to be important in controlling grazing depth (Woodward, 1998).

The decision not to incorporate drainage holes meant that control of moisture status was critical and this was achieved using hand watering and visual assessment of moisture status of the growing medium. An alternative strategy would be to provide drainage holes, but place the sward boxes in a second box without holes only for the duration of each test so that water and/or growing medium were not lost. A soil-based compost was chosen as the growing medium as this had a consistent specification in terms of the component materials included and also supplied nutrients within a declared 
range and was thus less variable in texture, structure and nutrient composition than soil. It also had a lower bulk density and therefore the sward box was lighter allowing it to be handled and weighed accurately more easily. Other growing media which have properties that make them suitable for use in cutting managements for mini-swards grown in pots (e.g. Hernandez Garay et al., 1999), would also have to provide sufficient anchorage for the tillers if they were to withstand the forces applied by bites during the tests which tend to result in uprooting of tillers.

A major issue in the design of the method was the contrasting seed sizes of different varieties (2.1 and 3.8 g per thousand seeds for the diploid and tetraploid varieties, respectively). Following recommended UK fieldscale sowing rates for statutory 'value for cultivation and use' (VCU) testing procedures (DEFRA, 1998) for diploid $\left(2.2 \mathrm{~g} \mathrm{~m}^{-2}\right)$ and tetraploid $\left(3.3 \mathrm{~g} \mathrm{~m}^{-2}\right)$ perennial ryegrass variety trials meant that very small quantities of seed would have been sown in each box ( 0.8 and 1.2 $\mathrm{g}$ for diploid and tetraploid, respectively) and it was felt that broadcasting such small quantities would not create a sufficiently even distribution of plants across the surface area of the sward box or a sufficiently dense sward that would reflect densities in the field within a reasonable timescale. The sowing rates used to establish paddocks in the adjoining grazing experiment were equivalent to $3 \mathrm{~g} \mathrm{~m}^{-2}$ and $4 \mathrm{~g} \mathrm{~m}^{-2}$ for the diploid and tetraploid varieties, which equated to 1429 and 1053 seeds $\mathrm{m}^{-2}$ respectively. Using the temporary sowing grid with 25-mm squares ensured an even sowing with a sowing rate of 1600 seeds $\mathrm{m}^{-2}$ and there appeared to be a high germination percentage for all four varieties. The sowing procedure took approximately $20 \mathrm{~min}$ for each box and provided the opportunity for seed cleaning. A further refinement of the technique would be to sow extra seeds in each grid section and then thin down to one plant to ensure a plant is established in every location in the grid.

The pre-test management of the micro-swards in 2003 was to take the first harvest 7 weeks after sowing, followed by two further cuts on a 3 -week cycle and then the tests were made on a 3-week regrowth. Hence, the tests were standardised by a regrowth period following cutting to a standard height. An alternative approach would be to test each variety at the same sward state, examples of which might include the same sward surface height (using a sward stick), compressed sward height (using a rising platemeter), extended tiller length (using a ruler), total mass or live leaf mass above the root/shoot interface (Hodgson et al., 1981). The use of mechanical clippers was assessed in the development phase during 2002 but was found to be less satisfactory than hand clipping with scissors because the relativelyunsupported sward canopy tended to part longitudinally down the box and hang over the sides in the later stages of the regrowth period. Cutting by hand with scissors enabled more precise control of stubble height through gathering and extending clusters of adjacent tillers and required approximately $15-20 \mathrm{~min}$ for each box.

\section{Short-term tests of bite mass using individual cattle}

The sward box technique depended on precise weighing of the boxes before and after each test using a scale which weighed to $0.1 \mathrm{~g}$ accuracy. Even higher levels of precision $(<0.01 \mathrm{~g})$ would be possible through use of comparator balances. These have a very high resolution of up to 50 million points, are distinguished by extremely high repeatability but require to be sited in environments with very high levels of climate control - beyond the scope of the present study.

The sward box tests were conducted with individual animals which may have affected their behaviour (Penning et al., 1993; Rind \& Phillips, 1999). Therefore the heifers in the present experiment were trained in the procedure so that they were very well accustomed to being handled. The test arena was adjacent to the holding paddock so that each test heifer was close to a companion animal and in full view of the other two, which tended to gather round and also observe the test. Therefore, in order to reduce the possibility of animals behaving abnormally it is vital that any large scale variety testing scheme should be based on using a pool of trained animals in an arena that is designed to allow the animals to be handled quietly and calmly.

\section{Applicability of the sward box methodology to grass variety screening}

Daily intake is the product of intake rate and eating time (Allden \& Whittaker, 1970), where intake rate is the product of bite mass and biting rate. The sward affects intake through constraints on bite mass, by morphological differences for example, and this is why the most important component of daily herbage intake is bite mass (Chacon \& Stobbs, 1976). Animals have only limited opportunity to compensate for low bite mass by increasing eating time because of the time required for other essential behaviours such as rumination, grooming and socialisation. In the present 
experiment, fresh bite mass was significantly higher for the tetraploid varieties than the diploids in 2003 but, whilst the tetraploids tended to be higher on a DM basis, this was not significant. Gilliland et al. (2002) compared perennial ryegrass varieties in a frequent cutting trial with 8 harvests over the season and measured morphological and chemical traits. Significant differences associated with ploidy were recorded, with tetraploid varieties having higher values than diploids in some plant morphological (bulk density, proportion of lamina, green leaf mass) and chemical (water soluble carbohydrate) characters which have been associated with higher intake. However, Orr et al. (2003, 2004b) did not find significant correlations between intake of perennial ryegrass varieties for continuously-stocked sheep and green leaf mass or water soluble carbohydrate concentration and suggested that other traits should be examined which affect bite mass and intake.

\section{Micro-swards vs field scale measurements}

There were no significant differences between these four varieties when bite mass was measured either under rotational stocking for groups in the field or when offered as regrowths in micro-swards to individual cattle. However, this should not be taken to mean that there would be no differences in bite mass under other grazing managements such as continuous stocking with cattle following sward height guidelines and this should be tested.

\section{Conclusion}

The sward box methodology provides a rapid, lowcost assessment method with a low seed requirement to screen for intake traits during breeding programmes and during variety evaluation. Whilst under intermittent defoliation the rankings were similar for DM bite mass whether assessed using sward boxes offered to individual heifers or measured in groups grazing paddocks, there were no significant differences between the four varieties. Now there is a need to develop further this methodology in order to allow small-scale simulation of continuous stocking conditions, where intake differences have been shown with sheep (Orr et al., 2003, 2004b). This might be achieved, for example, using a modification of a frequent castellated cutting (Smith, 1968) approach to simulate bites during the preparation of micro-swards before testing.

\section{Acknowledgments}

This work was funded by the UK Department for Environment, Food and Rural Affairs and was carried out in accordance with the welfare standards approved by IGER's Ethical Review Procedure. IGER is supported by the UK Biotechnology and Biological Sciences Research Council.

\section{References}

Allden, W.G. \& I.A. Whittaker, 1970. Determinants of herbage intake by grazing sheep - interrelationship of factors influencing herbage intake and availability. Austr J Agric Res 21: 755766.

Barrett, P.D., D.A. McGilloway, A.S. Laidlaw \& C.S. Mayne, 2003. The effect of sward structure as influenced by ryegrass genotype on bite dimensions and short-term intake rate by dairy cows. Grass Forage Sci 58: 2-11.

Barrett, P.D., A.S. Laidlaw, C.S. Mayne \& H. Christie, 2001. Pattern of herbage intake rate and bite dimensions of rotationally grazed dairy cows as sward height declines. Grass Forage Sci 56: 362373.

Beerepoot, L.J. \& R.E. Agnew, 1997. Breeding for improved herbage quality in perennial ryegrass. In: J.R. Weddell (Ed.), Seeds of Progress. Occasional Symposium 31, Br Grassland Socety pp. 135-145.

Black, J.L. \& P.A. Kenney, 1984. Factors affecting diet selection by sheep. II Height and density of pastures. Austr J Agric Res 35: 565-578.

Chacon, E. \& T.H. Stobbs, 1976. Influence of progressive defoliation of a grass sward on the eating behaviour of cattle. Austr J Agric Res 27: 709-727.

Concha, M.A. \& A.M. Nicol, 2000. Selection by sheep and goats for perennial ryegrass and white clover offered over a range of sward height contrasts. Grass Forage Sci 55: 47-58.

Department for Environment, Food \& Rural Affairs, DEFRA; formerly MAFF 1998. United Kingdom National List Trials Herbage VCU Procedures, Plant Varieties and Seeds Division, Cambridge. pp. 36.

Gilliland, T.J., P.D. Barrett, R.L. Mann, R.E. Agnew \& A.M. Fearon, 2002. Canopy morphology and nutritional quality traits as potential grazing value indicators for Lolium perenne varieties. J Agric Sci Camb 139: 257-273.

Greenwood, G.B. \& M.W. Demment, 1988. The effect of fasting on short-term cattle grazing behaviour. Grass Forage Sci 43: 377386.

Hazard, L., A. De Moraes, M. Betin, R. Traineau \& J.-C. Emile, 1998. Perennial ryegrass cultivar effects on intake of grazing sheep and feeding value. Ann Zootech 47: 117-125.

Hernandez Garay, A., C. Matthew \& J. Hodgson, 1999. Tiller size/density compensation in perennial ryegrass miniature swards subject to differing defoliation heights and a proposed productivity index. Grass Forage Sci 54: 347-356.

Hodgson, J., R.D. Baker, A. Davies, A.S. Laidlaw \& J.D. Leaver, 1981. Sward Measurement Handbook, The British Grassland Society, GRI Hurley, Maidenhead, U.K. 
Laca, E.A., E.D. Ungar, N.G. Seligman, M.R. Ramey \& M.W. Demment, 1992a. An integrated methodology for studying shortterm grazing behaviour of cattle. Grass Forage Sci 47: 81-90.

Laca, E.A., E.D. Ungar, N.G. Seligman \& M.W. Demment, 1992b. Effects of sward height and bulk density on bite dimensions of cattle grazing homogeneous swards. Grass Forage Sci 47: 91-102.

Lawes Agricultural Trust, 1995. Genstat 5 Procedure Library Manual, Release 3[3]. The Numerical Algorithms Group, Oxford, U.K.

McGilloway, D.A., A. Cushnahan, A.S. Laidlaw, C.S. Mayne \& D.J. Kilpatrick, 1999. The relationship between level of sward height reduction in a rotationally grazed sward and short-term intake rates of dairy cows. Grass Forage Sci 54: 116-126.

Mitchell, R.J., J. Hodgson \& D.A. Clark, 1991. The effect of varying leafy sward height and bulk density on the ingestive behaviour of young deer and sheep. Proc NZ Soc Anim Prod 51: 159-165.

Newman, J.A., A.J. Parsons \& A. Harvey, 1992. Not all sheep prefer clover: Diet selection revisited. J Agric Sci Camb 119: 275-283.

Newman, J.A., P.D. Penning, A.J. Parsons, A. Harvey \& R.J. Orr, 1994. Fasting affects intake behaviour and diet preference of grazing sheep. Anim Beh 47: 185-193.

Orr, R.J., J.E. Cook, R.A. Champion, P.D. Penning \& A.J. Rook, 2003. Intake characteristics of perennial ryegrass varieties when grazed by sheep under continuous stocking management. Euphytica 134: $247-260$.

Orr, R.J., S.M. Rutter, N.H. Yarrow, R.A. Champion \& A.J. Rook, 2004a. Changes in ingestive behaviour of yearling dairy heifers due to changes in sward state during grazing down of rotationallystocked ryegrass or white clover pastures. Appl Anim Behav Sci 87: 205-222.

Orr, R.J., J.E. Cook, R.A. Champion \& A.J. Rook, 2004b. Relationships between morphological and chemical characteristics of perennial ryegrass varieties and intake by sheep under continuous stocking management. Grass Forage Sci 59: 389-398.

Patterson, D.M., D.A. McGilloway, A. Cushnahan, C.S. Mayne \& A.S. Laidlaw, 1998. Effect of duration of fasting period on shortterm intake rates of lactating dairy cows. Anim Sci 66: 299-305.

Penning, P.D., A.J. Parsons, J.A. Newman, R.J. Orr \& A. Harvey, 1993. The effects of group size on grazing time in sheep. Appl Anim Behav Sci 37: 101-109.

Rind, M.I. \& C.J.C. Phillips, 1999. The effects of group size on the ingestive and social behaviour of grazing dairy cows. Anim Sci 68: 589-596.

Rook, A.J., A. Harvey, A.J. Parsons, R.J. Orr \& S.M. Rutter, 2004. Bite dimensions and grazing movements by sheep and cattle grazing homogeneous perennial ryegrass swards. Appl Anim Behav Sci 88: 227-242.

Smith, A., 1968. Sward growth in relation to pattern of defoliation. J Br Grassland Soc 23: 294-298.

Ungar, E.D. \& N. Ravid, 1999. Bite horizons and dimensions for cattle grazing herbage to high levels of depletion. Grass Forage Sci 54: 357-364.

Woodward, S.J.R., 1998. Bite mechanics of cattle and sheep grazing grass-dominant swards. Appl Anim Behav Sci 56: 203-222. 